Portland State University

PDXScholar

\title{
Phase Transitions and In Situ Dynamics of Crystal Grain Formation of Alumina Nanotubes Templated by Vertically Aligned Carbon Nanotubes
}

L. F. Lampert

Portland State University

A. Barnum

Portland State University

S. W. Smith

Oregon State Uiversity

J. F. Conley

Oregon State University

Jun Jiao

Portland State University, jiaoj@pdx.edu

Follow this and additional works at: https://pdxscholar.library.pdx.edu/mengin_fac

Part of the Materials Science and Engineering Commons, and the Mechanical Engineering Commons Let us know how access to this document benefits you.

\section{Citation Details}

Lampert, L. F., Barnum, A., Smith, S. W., Conley, J. F., \& Jiao, J. (2015). Phase transitions and in situ dynamics of crystal grain formation of alumina nanotubes templated by vertically aligned carbon nanotubes. RSC Advances, 5(83), 68251-68259.

This Article is brought to you for free and open access. It has been accepted for inclusion in Mechanical and Materials Engineering Faculty Publications and Presentations by an authorized administrator of PDXScholar. Please contact us if we can make this document more accessible: pdxscholar@pdx.edu. 


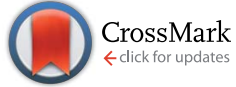

Cite this: RSC Adv., 2015, 5, 68251

Received 25th June 2015 Accepted 30th July 2015

DOI: $10.1039 / c 5 r a 12337 b$

www.rsc.org/advances

\title{
Phase transitions and in situ dynamics of crystal grain formation of alumina nanotubes templated by vertically aligned carbon nanotubes $\uparrow$
}

\author{
L. F. Lampert, ${ }^{a}$ A. Barnum, ${ }^{a}$ S. W. Smith, ${ }^{\text {J J. F. Conley Jr. }}{ }^{\text {b }}$ and J. Jiao*a \\ Phase transitions of amorphous alumina (a-alumina) nanotubes grown by atomic layer deposition and \\ templated by carbon nanotubes were investigated with thermal annealing, transmitted Kikuchi electron \\ diffraction, electron-irradiation-induced crystallization, X-ray diffraction, and X-ray photoelectron \\ spectroscopy. The resulting, engineered alumina nanotube arrays demonstrate a large range of tunable \\ phases that are vital for understanding how alumina nanotube arrays can be applied for uses within \\ biotechnology, catalysis, and other academic and industrial uses.
}

\section{Introduction}

Aluminum oxide, or alumina, is a technologically pervasive material finding applications due to its low electrical and thermal conductivity, high melting point, and its benign nature with mammalian biological systems where it can be used for immunoisolation and act as an antigen vector in free-particle or anchored format. ${ }^{1-3}$ It is primarily used as a catalyst, catalyst support, and adsorbent within industry. ${ }^{4-6}$ With many of these applications, it is still poorly understood how the various metastable and stable crystalline forms affect the performance of alumina. The most well-known, low- and high-temperature stable forms are $\gamma$-alumina and $\alpha$-alumina, respectively. At low-temperatures there exists a large set of near-polymorphic phases, which appear with increasing temperature approaching the thermodynamically stable $\alpha$-alumina phase. These metastable polytypes are: $\alpha^{\prime}, \lambda, \beta, \gamma, \eta, \kappa, \delta, \chi, \theta^{\prime \prime}$, and $\theta .^{7-9}$ The number of known metastable phases continues to increase, with slight ambiguity derived from interstitial atoms provided by hydrogen, carbon, and various other sources available during various reported phase transition experiments. This large set of alumina metastable phases requires additional understanding of their phase transitions at the nano-scale having engineered geometries.

Nanostructures composed of alumina, specifically 1D alumina (nanowires and nanotubes), continue to be developed using techniques such as surfactant templating, ${ }^{10}$ aluminum

\footnotetext{
${ }^{a}$ Department of Physics and Mechanical \& Materials Engineering, Portland State University, P.O. Box 751, Portland, OR 97207-0751, USA. E-mail: jiaoj@pdx.edu; Tel: +15037254228

${ }^{b}$ School of Engineering \& Computer Science, 3089 Kelley Engineering Center, Oregon State University, Corvallis, OR 97331-5501, USA

$\dagger$ Electronic supplementary information (ESI) available. See DOI: $10.1039 / \mathrm{c} 5 \mathrm{ra12337b}$
}

foil anodization, ${ }^{\mathbf{1 1}, \mathbf{1 2}}$ chemical vapor deposition (CVD), ${ }^{\mathbf{1 3}}$ and thermal evaporation. ${ }^{14}$ With each of these techniques, there are different engineering obstacles to overcome in tailoring alumina nanowires/nanotubes for flexible large-scale patterning that could enable various technological applications. Specifically, there are advantages to having anchored arrays of vertically aligned alumina nanowires/nanotubes that can be harnessed with delivery of active biological effectors, high surface area catalysts and catalyst supports, easily tunable liquid repellent films, and with other applications such as advanced optical coatings. With the previously mentioned techniques, only aluminum foil anodization, CVD, and thermal evaporation have demonstrated a capability to produce vertically aligned alumina nanowires. Both CVD and thermal evaporation methods have been shown to create short-range alumina nanowire arrays; however, patterning and growth control are challenging. The only other method capable of producing such arrays, aluminum foil anodization, creates high density arrays with a limited amount of control and complicated recipes.

In this paper we utilize vertically aligned carbon nanotubes (CNTs) as templates for alumina nanotube formations. Other methods for producing CNT networks besides vertically aligned CNTs via PECVD have been implemented on flat surfaces, round objects, porous substrates, and with self-standing and cross-linked networks. ${ }^{35}$ Additionally, CNTs are capable of being dispersed in solvents such as DMSO and directly deposited onto fused silica. ${ }^{36}$ Although the method of using vertically aligned CNTs as templates has been applied elsewhere with its global initiation occurring around the year 2003,,${ }^{15,16}$ little work has been done to understand how CNT-templated alumina nanotubes behave with thermal annealing. Since the as-deposited oxide coating by the atomic layer deposition (ALD) process is generally amorphous, crystallization of oxide materials is required. It is also essential to understand the effects of crystallization process, as constraint of the nano-scale oxide 
coatings will cause significant changes in grain size, nucleation, and phase transformations. Herein we attempt a comprehensive study of CNT-templated alumina as it transforms from an amorphous state to first $\gamma$-alumina with an interesting route towards other metastable states suggesting a crystal grain growth mechanism unique to nano-scale oxide tube structures. It is expected that this study will also contribute knowledge for a better understanding of other low-dimensional oxide nanostructures so to allow a more diverse set of applications to be realized in future endeavors.

\section{Materials and experimental procedure}

For CNT growth, a thin film of Ni catalyst was deposited via magnetron DC sputtering to a final thickness of $3.5 \mathrm{~nm}$ onto a $\mathrm{SiO}_{2} / \mathrm{Si}$ wafer with $300 \mathrm{~nm}$ of thermal oxide. The wafers were then loaded into a plasma-enhanced chemical vapor deposition (PECVD) system with a ramp rate of $300{ }^{\circ} \mathrm{C} \mathrm{min}^{-1}$ to a final growth temperature of $800{ }^{\circ} \mathrm{C}$. During the ramp stage, a reducing environment was achieved by delivering $200 \mathrm{sccm}$ of $\mathrm{NH}_{3}$. Once at growth temperature, a DC plasma was initiated at the platen along with $50 \mathrm{sccm}$ of $\mathrm{C}_{2} \mathrm{H}_{2}$. Once the desired growth period had completed, both gases were turned off and the growth chamber was kept at vacuum until cooled to room temperature. As-grown CNTs have an average diameter of $56 \mathrm{~nm}$, length of $\sim 7.5 \mu \mathrm{m}$, and spacing of $100-300 \mathrm{~nm}$. The resulting, as-grown vertically aligned CNTs were loaded into an Arradiance Gemstar ALD system maintained at $175^{\circ} \mathrm{C}$ during 191 cycles of $500 \mathrm{~ms}$ pulses of trimethylaluminum (TMA) and $\mathrm{H}_{2} \mathrm{O}$ separated by $40 \mathrm{~s} \mathrm{~N}_{2}$ purges for an ultimate thickness of $25 \mathrm{~nm}$.

\section{Thermal annealing}

The as-grown amorphous alumina (a-alumina) vertically aligned nanowires (VANWs) were inserted into a horizontal tube furnace for thermal annealing. The tube furnace was kept at atmospheric pressure in ambient conditions throughout the annealing and cooling process. All thermal anneals were performed with a $100{ }^{\circ} \mathrm{C} \mathrm{min}^{-1}$ ramp rate with a stage I temperature of $950{ }^{\circ} \mathrm{C}$ and stage $\mathrm{II} / \mathrm{II}^{\prime}$ temperature of $1200{ }^{\circ} \mathrm{C}$. The annealing processes for ALD alumina coated CNTs are illustrated in Fig. 1.

\section{Transmitted Kikuchi electron diffraction (TKD)}

Transmitted Kikuchi diffraction (TKD) was performed with a Zeiss Sigma VP scanning electron microscope (SEM) equipped with an Oxford EBSD camera. For all maps, an accelerating voltage of $30 \mathrm{kV}$ was used. The samples were first loaded onto Pelco 200 mesh $\mathrm{Cu}$ Quantifoil grids by gentle scraping of the asgrown VANWs. Next, the grids were loaded onto a custom-made TKD holder capable of holding six grids at the desired pre-tilt angle. The TKD holder was held at $\sim 10^{\circ}$ during acquisition of Kikuchi patterns. $4 \times 4$ binning, $500 \mathrm{~ms}$ acquisition time per frame, and 4 frame averaging were selected for all mapping analysis.

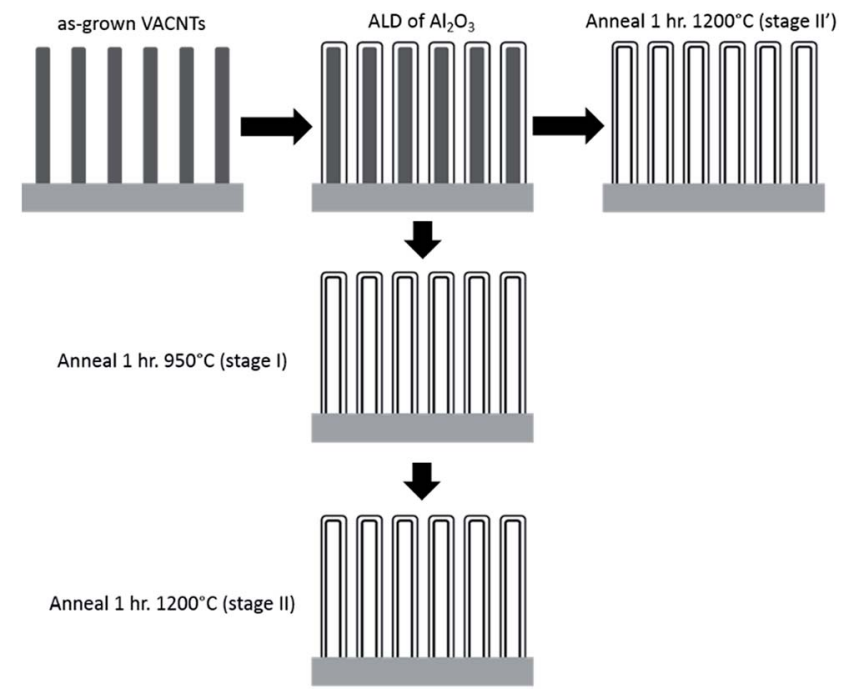

Fig. 1 Schematic overview of experimental procedure used for annealing vertically aligned alumina nanotubes template with vertically aligned carbon nanotubes. All annealing was completed in a horizontal tube furnace within atmosphere pressure at ambient conditions. Stage I annealing was accomplished with intact CNTs at $950{ }^{\circ} \mathrm{C}$, stage || at $1200^{\circ} \mathrm{C}$ directly following stage I, and stage II' represents annealing at $1200^{\circ} \mathrm{C}$ with intact CNTs.

\section{XPS analysis}

XPS measurements were carried out with a Physical Electronics (PHI) Versaprobe II equipped for X-ray photoelectron spectroscopy (XPS), Auger electron spectroscopy (AES), and ultraviolet photoelectron spectroscopy (UPS) functionalities using $\mathrm{Al} \mathrm{K}_{\alpha}$ $(1486.6 \mathrm{eV})$. High resolution spectra were recorded with a pass energy of $29.35 \mathrm{eV}$. All spectra were recorded at $45^{\circ}$ to the hemispherical analyzer using both electron and $\mathrm{Ar}^{+}$neutralizers. Since no significant charging or shift in carbon peaks were observed, the VANWs were scanned uncoated. Spectral deconvolutions were achieved with PHI Multipak software using a Shirley background and pseudo Voigt distribution functions.

\section{XRD analysis}

XRD measurements were performed with a Rigaku Ultima IV operating at $40 \mathrm{kV}$ under $44 \mathrm{~mA}$ on a copper target at room temperature. A $\theta$ measurement on a thin film stage was used, with a scan range from $5-90^{\circ}$ using $0.01^{\circ}$ per step and a full integration time of 10 seconds per step. Analysis of the data was completed on the Rigaku PDXL software using whole powder pattern fitting (WPPF) and Rietveld fitting to determine corresponding alumina phases in the ICDD and related composition percentages.

\section{TEM characterization \& electron-irradiation-induced crystallization}

Electron beam induced phase changes of a- $\mathrm{Al}_{2} \mathrm{O}_{3}$ were carried out with an FEI Tecnai F20 transmission electron microscope (TEM) at $200 \mathrm{kV}$. The images were recorded with $1.2 \mathrm{~s}$ 
integration times and with an addition $0.6 \mathrm{~s}$ between the images for saving. An open objective aperture was used, along with a 2 $\mathrm{mm}$ first condenser and a $150 \mu \mathrm{m}$ second condenser aperture. The diffraction patterns were recorded using similar settings, except that a $10 \mu \mathrm{m}$ second condenser was used. Current density was measured by the screen ammeter to achieve $4 \times 10^{6} \mathrm{~A} \mathrm{~m}^{-2}$ for crystallization seeding. This translates to an electron dose rate of $2.5 \times 10^{25} \mathrm{e} / \mathrm{s} \mathrm{\textrm {m } ^ { 2 }}$. Based on published dose rates required for alumina crystallization, ${ }^{28}$ the onset of nanocrystal formation was observed after no less than 25 minutes of beam exposure in diffraction mode. The dose rate at seeding leads to crystallization after $2 \mathrm{~s}$ of exposure, matching the observed crystallization dose rates observed previously. ${ }^{28}$ Upon alumina crystal seeding, a dose per frame of $1.85 \times 10^{24} \mathrm{e} / \mathrm{m}^{2}$ was used to visualize the dynamics of crystal grain propagation.

\section{Results and discussion}

As-deposited amorphous alumina nanotubes were annealed in three separate stages as depicted in Fig. 1. Annealing stages I and II were executed sequentially to determine if the presence of CNTs plays a role in the phase change path of the alumina nanotubes. Stage II' was established to differentiate stage II, which did not have carbon nanotubes present during annealing (CNTs burned out in stage I, prior to stage II) and hence should be driven to a different crystallographic state. CNTs are known to combust in a temperature range of $550-750{ }^{\circ} \mathrm{C}$ derived from thermogravimetric analysis. ${ }^{33}$ Multi-walled CNTs (MWCNTs), such as those used in this work, have onset combustion temperatures of $633{ }^{\circ} \mathrm{C} .{ }^{34}$ TEM images were acquired of the asdeposited alumina nanotubes/CNT structure in addition to a sample from each annealing stage. As seen in Fig. 2b (inset), the as-deposited structure exhibits a thick, multilayered carbon nanotube core with a bamboo-like structure typical for PECVDgrown CNTs. ${ }^{17}$ Also seen in Fig. $2 \mathrm{c}$ is a portion of a Ni catalyst tip that is characteristic for the tip-based growth utilized for this study. ${ }^{18}$ The Ni film (3.5 nm thick) undergoes rapid thermal annealing and treatment of a plasma localized to the catalyst film. This process causes the film to coalesce into nanoparticles from which CNTs extend. As evidenced by the $\mathrm{Ni}$ catalyst present in the ends of the CNTs, the growth is tip-based. During the beginnings of growth with larger, coalesced catalyst nanoparticles related to tip-based CNT growth, carbon sections formed on the surface have sufficient time for diffusion prior to complete formation of a hemispherical carbon cap. ${ }^{32}$ Additionally, the corresponding electron diffraction pattern depicted in Fig. 2a confirms the amorphous nature of the alumina coating with amorphous carbon rings present. In Fig. 2d-f, corresponding to stage I annealing, there exists a defined crystallization as revealed by both electron diffraction and bright field imaging. The predominant phase, from electron diffraction, is $\gamma$-alumina with some rings matching the $\eta$-alumina phase. For stage II, it can be seen in Fig. $2 \mathrm{~g}$ that more fine structure within the inner rings is present. The $\gamma$-alumina phase remains with disappearance of the previously defined $\eta$ alumina phase and emergence of a new phase having cubic symmetry with space group: $F d \overline{3} m$. Then, with the stage II $^{\prime}$ annealing process, the $\gamma$-alumina continues to remain with the removal of the cubic phase present in stage II and emergence of a $\theta$-alumina phase, as depicted in Fig. $2 \mathrm{j}$. It can also be seen there is a clear change in the grain structure between all annealing processes. In order of apparent grain size from largest to smallest, it is stages $\mathrm{II}^{\prime}$, II, and I. The dark regions within Fig. 2f, i and 1 originate from the insertion of a $250 \mu \mathrm{m}$ objective aperture. If the crystal grains within the sample are rotated relative to one another, the inserted objective aperture will select Bragg reflections from one crystal and not the other. The apparent gradient of contrast from light gray to black is derived from the orientation of crystallites relative to the incident electron beam direction. The higher contrast regions are in closest alignment with the incident electron beam and a zone axis of a given crystallite. SEM images of the as-deposited alumina sample and each annealed VANW array is depicted in Fig. 3a-d indicating that throughout all annealing states, the vertical alignment of the alumina nanotubes was conserved.

Electron diffraction and TEM imaging help to characterize the overall crystallinity and morphology, however, it is difficult to gain insight into the spatial distribution of crystal phases due to the low throughput of general electron diffraction in the TEM. In order to better understand the spatial distributions of each alumina phase, we conducted maps of TKD patterns on each annealed alumina sample. TKD is a relatively new
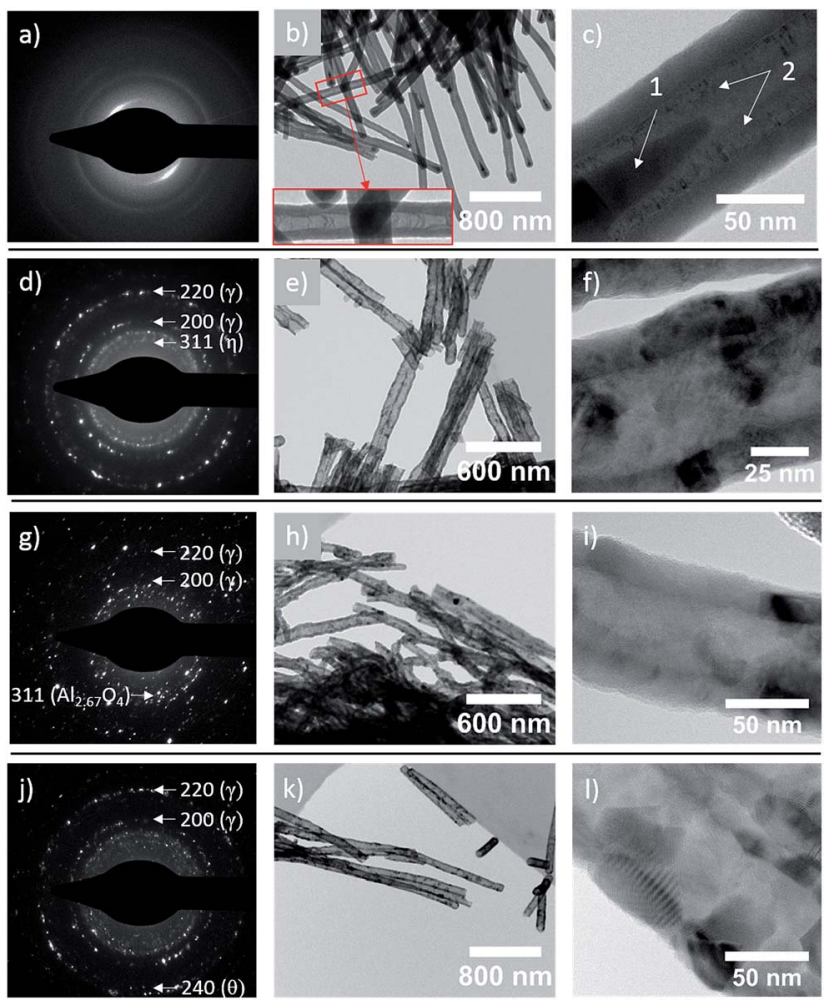

Fig. 2 ( $a, d, g$ and j) Diffraction patterns, (b, e, hand k) low-magnification brightfield TEM images, and (c, $f$, i and l) high-magnification brightfield TEM images of as-coated, stage I, stage II, and stage II' samples, respectively. The Ni catalyst tip and CNT walls are labelled as 1 and 2 in (c), respectively. 

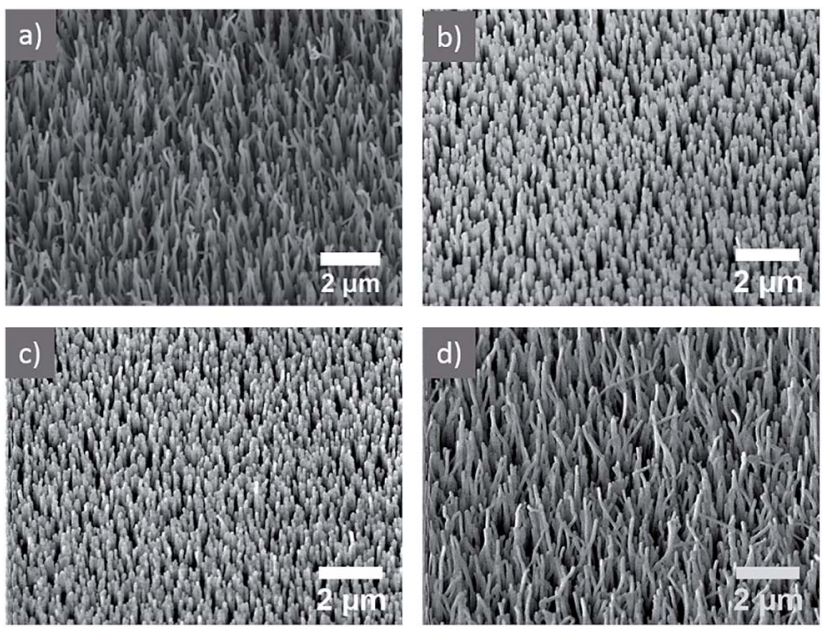

Fig. 3 (a-d) SEM images of as-deposited, stage I, II, and II' annealed alumina nanotube samples, respectively. Throughout all annealing stages, the vertical alignment of the alumina nanotubes was conserved.

technique with development for use with nanomaterials occurring within the past 4 years. ${ }^{\mathbf{1 9 , 2 0}}$ Kikuchi patterns have been used in the SEM for nanowire analysis, however it was limited to electron backscatter diffraction (EBSD) and not TKD. ${ }^{21}$ To the best of our knowledge, this is the first time TKD is used for phase identification and distribution analysis of nanowires in an SEM. Using the same samples as prepared for TEM analysis, each grid was loaded onto a custom-made pre-tilt TKD holder after the grid was coated $5 \mathrm{~nm}$ amorphous carbon coating avoid charging. All maps with band contrast and phase distributions along with phase fraction pie charts are depicted in Fig. 4. Current density was measured to be $\sim 3.5 \times 10^{7} \mathrm{~A} \mathrm{~m}^{-2}$. At this current density, crystallization seeding is possible in amorphous alumina regions. However, all samples scanned with TKD were crystalline and did not exhibit any phase

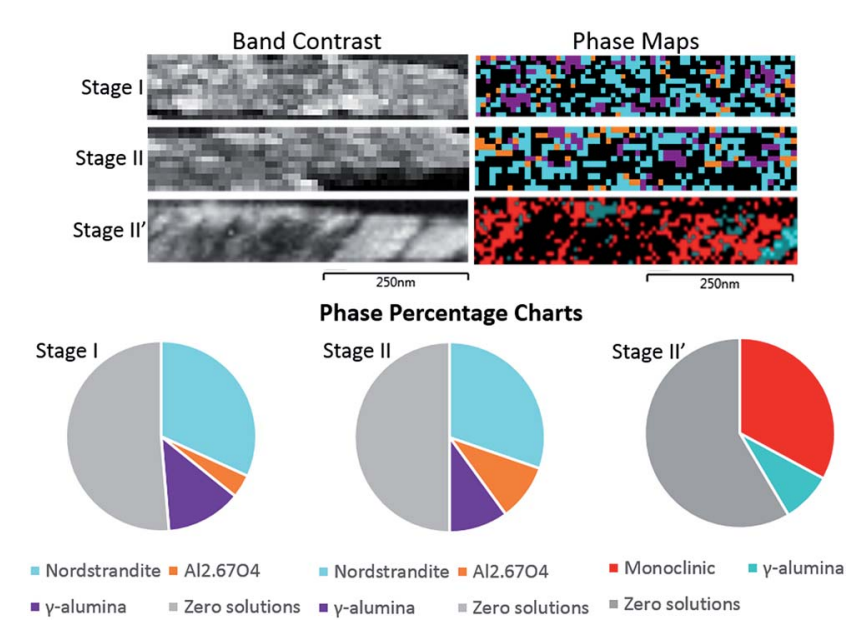

Fig. 4 Depicted above are the Kikuchi band contrast (top left) and phase maps (top right) with corresponding composition pie charts (lower). changes after TKD mapping. Additionally, the time per point was kept at $\sim 2 \mathrm{~s}$ and prior to mapping the beam was parked onto the selected nanotube for $10 \mathrm{~s}$ to confirm there were no changes observed in the resulting Kikuchi lines projected onto the EBSD camera. As seen in Fig. 4, the stage I annealed sample's Kikuchi pattern map matches the majority of the detected phases to the triclinic Nordstrandite (ICSD\#: 16018), with the remaining matched phases to $\mathrm{Al}_{2.67} \mathrm{O}_{4}$ (ICSD\#: 69213) and $\gamma$-alumina (ICSD\#: 30267). The stage II annealed sample, seen in Fig. 4, has Kikuchi matches to the same set of phases as the stage I sample with changes in the overall content and distribution. The amount of triclinic Nordstrandite and $\gamma$ alumina decreases with evidence of larger grains of $\mathrm{Al}_{2.67} \mathrm{O}_{4}$. Finally, as seen in Fig. 4, the stage $\mathrm{II}^{\prime}$ annealed sample loses all matches with the triclinic Nordstrandite and instead is primarily matched with a monoclinic alumina (ICSD\#: 66560) and some remaining $\gamma$-alumina grains. As expected, the overall quantity of detected $\gamma$-alumina decreased with increasing temperature and between stage II and II $^{\prime}$ annealed samples. Interestingly, the detected monoclinic alumina phase was only matched with the stage II' $^{\prime}$ alumina nanotube. The disordered

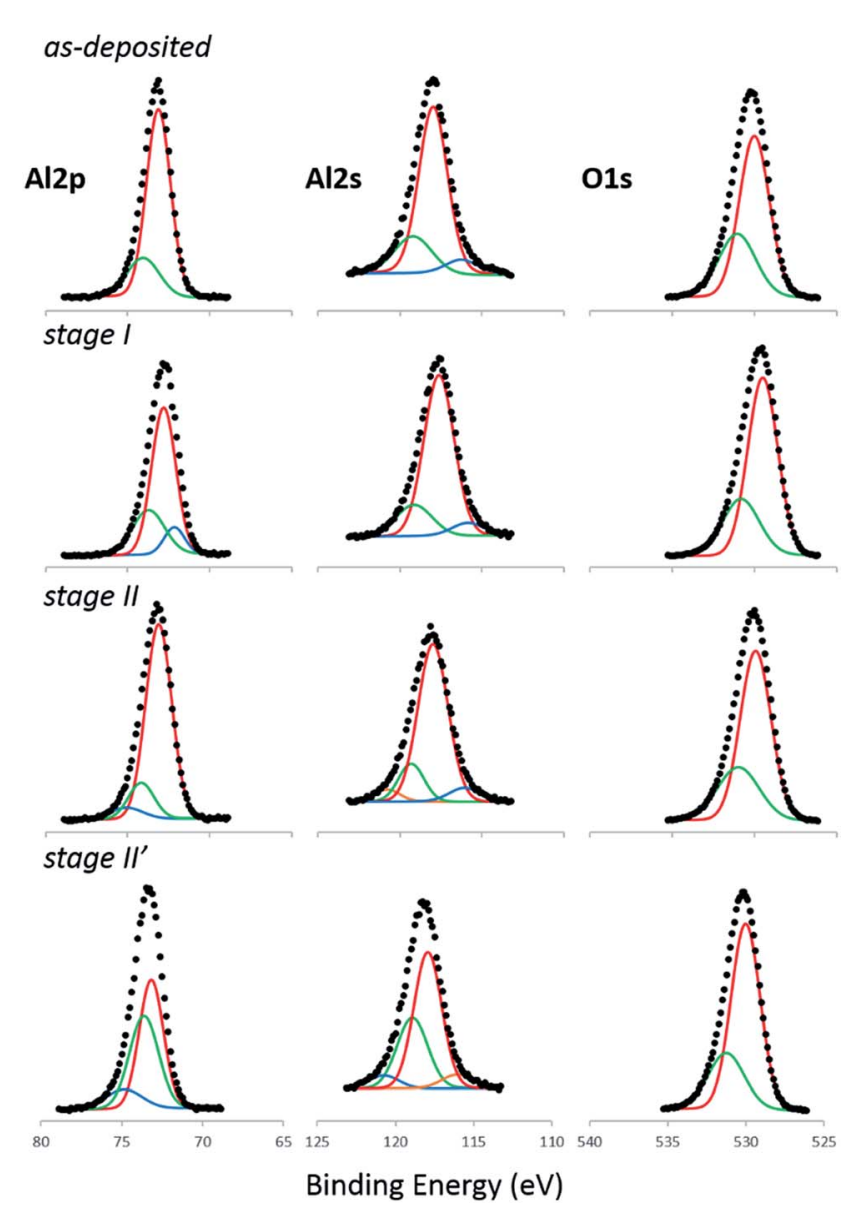

Fig. 5 High resolution XPS spectra with deconvolutions for Al2p, Al2s, and O1s peaks for as-deposited alumina nanotubes and stage I, II, II' annealed samples. The Al2 $p$ peak has a downshift for the stage I sample. Peak deconvolutions are assigned color in the order of decreasing area (highest-lowest): red, green, blue, and orange. 
spinel symmetry of $\gamma$-alumina becomes formally disordered to a simple fcc structure. This causes all octahedral and tetrahedral cation sites to be equivalent. ${ }^{8}$ For all maps, it should be noted the amount of zero solutions can attributed to the amount of overlapping metastable phases present within each alumina nanotube. The mean angular deviation (MAD) values were minimized while selecting phases present and related to those within XRD analysis.

High resolution scans of the Al2p, Al2s, and O1s peaks can be seen in Fig. 5. XPS analysis of alumina can be revealing in the fact it is possible to distinguish between tetrahedral and octahedral aluminum. The $\mathrm{Al}$ ion in the $\left[\mathrm{AlO}_{6}\right]^{9-}$ octahedron has a higher charge than the same $\mathrm{Al}$ ion within the $\left[\mathrm{AlO}_{4}\right]^{5-}$ tetrahedron. Additional chemical shifts occur with chemisorbed oxygen on aluminum $\left(\mathrm{Al}^{\mathrm{Chem}}\right)$ that is coordinated with less than 4 oxygen atoms on the surface. Therefore there are 4 major regions of interest with XPS analysis of alumina: $\mathrm{Al}^{0}$ (metallic aluminum), $\mathrm{Al}^{\mathrm{Tet}}, \mathrm{Al}^{\mathrm{Oct}}$, and $\mathrm{Al}^{\mathrm{Chem}} \cdot{ }^{22}$ Besides binding energy shifts, other methods have been reported to differentiate alumina phases including the FWHM of the Al2p peak where it is approximately 1.35 for $\alpha$-alumina and 2.5 for $\gamma$-alumina phases. ${ }^{23}$ The most marked shift in binding energy is seen in the Al2p peak after the stage I annealing process. The shift from $73.11 \mathrm{eV}$ to $72.79 \mathrm{eV}$ suggests a more metallic nature of the aluminum present within the nanotubes. Interestingly, this may be attributed to the presence of the CNTs during the stage I annealing process. Carbon is known to act as a reducing agent with alumina to extract elemental aluminum with the following reaction that is stable above $1770 \mathrm{~K}\left(1496.85^{\circ} \mathrm{C}\right) .{ }^{24}$

$$
\mathrm{Al}_{2} \mathrm{O}_{3}+3 \mathrm{C}=2 \mathrm{Al}+3 \mathrm{CO},\left(\Delta H_{298 \mathrm{~K}}^{0}=1344.1 \mathrm{~kJ} \mathrm{~mol}^{-1}\right)
$$

However, the temperature of the stage I annealing process, $950{ }^{\circ} \mathrm{C}$, is not high enough to be a thermodynamically favorable process according to the literature references of carbothermal reduction of alumina. Additionally, it is not likely an aluminum carbide was formed as the base temperature for such processes begins at $1000{ }^{\circ} \mathrm{C}$ to form $\mathrm{Al}_{4} \mathrm{C}_{3} \cdot{ }^{25}$ Both stage II and $\mathrm{II}^{\prime}$ have similar Al2p major peak (by area) values of $73.10 \mathrm{eV}$ and 73.16 $\mathrm{eV}$, respectively. Al2s and O1s peaks of all samples demonstrate consistent major peak locations. The separation of the major Al2p and O1s peaks $(\Delta \mathrm{BE})$ is a measure of the bonding where a purely ionic alumina should result in a larger separation than a mixed covalent oxide. This has been utilized in literature to determine the oxidic nature of annealed alumina films. ${ }^{23}$ As listed in Table 1, $\Delta \mathrm{BE}$ is largest for the amorphous ( $456.90 \mathrm{eV})$, as-deposited alumina with an initial decrease with stage I annealing and subsequent restoration of $\triangle B E$ separation with stage II and $\mathrm{II}^{\prime}$ annealing processes. Stage II' $\Delta \mathrm{BE}$ (456.88 eV) approaches the as-deposited alumina with a nearly matching value. In the literature it is generally believed the oxidic nature of alumina increases with annealing temperature and time, however, in this study, there is an observed, intermediate dip in the Al2p major peak location of the stage I sample resulting in a lower $\triangle \mathrm{BE}$ value (shift of $0.19 \mathrm{eV}$ ).

XRD analysis was completed for all samples with high resolution scans due to the complexity of overlapping alumina phases. Scan resolution was gradually increased until arriving at $0.01^{\circ}$ per step when no more additional peaks could be resolved. Also, high resolution scanning is the best method for Rietveld refinement as there are large amounts of entries in the ICDD for alumina phases. All XRD spectra are depicted in Fig. 6. As seen in Fig. 6a, the as deposited sample has several detectable graphite diffraction peaks resulted by the alumina encapsulated CNTs. The three-dimensional ( $h k l$ ) lines (101) and (102) are present with moderate intensity indicating little rotation between graphene layers of the CNTs. Other three-dimensional peaks (001) are present with suppressed intensity, both (002) and (004). The literature $2 \theta$ value for $\mathrm{ABAB}$ stacked graphite for the (002) peak is $\sim 26^{\circ}$ where peak broadening and increased diffraction angle can be attributed to increasing crystallite size. As seen in Fig. 6a, the (002) peak is slightly downshifted from $26^{\circ}$ with significant broadening compared to literature XRD spectra of flat, $\mathrm{ABAB}$ stacked graphite. Therefore, the dominant effect that can be attributed to the downshift and broadening of the (002) peak must be curvature of the graphite layers present with CNTs. Indeed, it has been demonstrated with increasing

Table 1 Extracted parameters from high resolution XPS spectra as depicted in Fig. 3. Values are listed in descending order of peak area

\begin{tabular}{|c|c|c|c|c|c|c|c|c|c|c|}
\hline Sample & $\mathrm{Al} 2 \mathrm{p}(\mathrm{eV})$ & $\Gamma(\mathrm{eV})$ & $\%$ area & $\mathrm{Al} 2 \mathrm{~s}(\mathrm{eV})$ & $\Gamma(\mathrm{eV})$ & $\%$ area & O1s $(e V)$ & $\Gamma(\mathrm{eV})$ & $\%$ area & $\Delta \mathrm{BE}(\mathrm{eV})$ \\
\hline \multirow[t]{2}{*}{ As deposited } & 73.11 & 1.73 & 78.48 & 117.97 & 2.08 & 70.75 & 530.01 & 2.16 & 66.24 & 456.90 \\
\hline & 74.04 & 2.32 & 21.52 & 119.19 & 2.74 & 20.75 & 531.05 & 2.66 & 33.76 & \\
\hline \multirow[t]{3}{*}{ stage I $\left(950^{\circ} \mathrm{C}\right)$} & 72.79 & 1.74 & 63.90 & 117.62 & 2.18 & 75.90 & 529.50 & 2.16 & 71.04 & 456.71 \\
\hline & 73.72 & 2.30 & 26.26 & 119.14 & 2.58 & 17.34 & 530.82 & 2.62 & 28.96 & \\
\hline & 72.15 & 1.44 & 9.84 & 115.85 & 2.34 & 6.76 & & & & \\
\hline & 75.06 & 2.33 & 5.73 & 116.07 & 2.24 & 7.03 & & & & \\
\hline & & & & 120.76 & 1.79 & 4.58 & & & & \\
\hline \multirow[t]{4}{*}{ Stage II' $\left(1200{ }^{\circ} \mathrm{C}\right)$} & 73.16 & 1.77 & 48.15 & 117.94 & 2.09 & 56.16 & 530.04 & 2.18 & 72.56 & 456.88 \\
\hline & 73.61 & 2.12 & 41.40 & 118.93 & 2.29 & 32.04 & 531.27 & 2.71 & 27.44 & \\
\hline & 74.86 & 2.62 & 10.45 & 120.77 & 2.29 & 5.95 & & & & \\
\hline & & & & 116.07 & 2.29 & 5.85 & & & & \\
\hline
\end{tabular}


curvature, the (002) peak both shifts downwards with increased peak broadening. ${ }^{\mathbf{2 6}}$ After the annealing process, the graphite peaks disappear in agreement with TEM observations, which do not detect any presence of residual CNT structure. Upon Rietveld refinement, the primary detected phases are cubic $\mathrm{Al}_{2.67} \mathrm{O}_{4}$ (ICSD\#: 249140), cubic $\gamma$-alumina (ICSD\#: 30267), and cubic $\eta$ alumina (ICSD\#: 68770) with calculated percentages of $78 \%$, $17 \%$, and $5 \%$ by wt, respectively. Two of the matched phases belong to the $F d \overline{3} m$ space group where the predominant metastable phase is reported to be $\gamma$-alumina with an accepted structural model of an ideal spinel. In reality, 8/3 aluminum vacancies have random distribution throughout the tetrahedral sites, demonstrating intrinsic disorder present within $\gamma$ alumina. ${ }^{7}$ Therefore, it suggests there exists other phases that

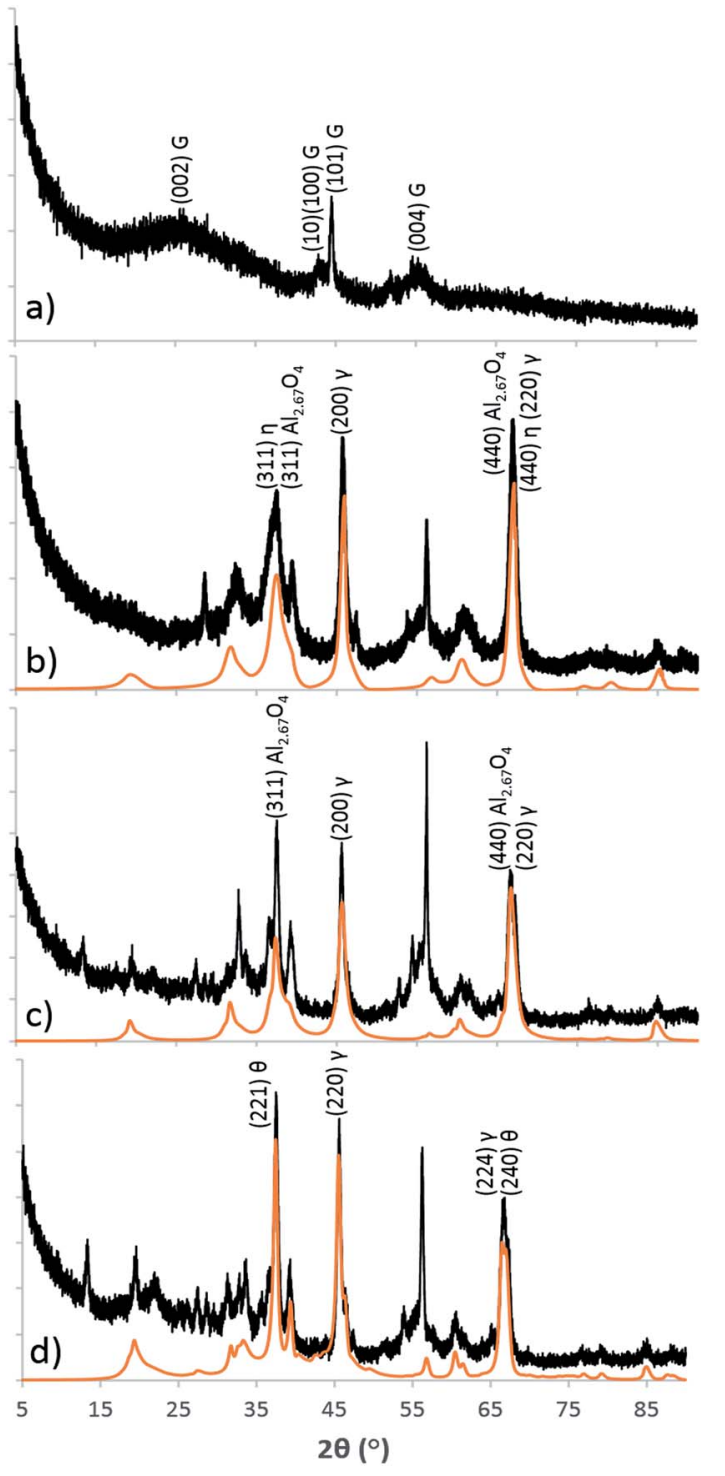

Fig. 6 (a-d) XRD spectra of as-deposited, stage I, stage II, and stage II' alumina nanotubes, respectively. Annealed samples are plotted with best fits from WPPF Rietveld refinements (orange line). Major peaks for corresponding phases are labelled. The sharp peak at $\sim 56^{\circ}$ is from the silicon substrate. are similar within the same space group of $F d \overline{3} m$. In fact, the Rietveld refinement of the stage I annealed sample would not converge when constrained to primarily registered $\gamma$-alumina phases within the ICSD. If one were to only rely upon electron diffraction, the conclusion would be strongly in favor of $\gamma$ alumina. It should also be noted that throughout all annealing processes, the $\gamma$-alumina phase persists. However, for stage $\mathrm{II}^{\prime}$, the $\gamma$-alumina symmetry switches from cubic to tetragonal. For the stage II annealing process, the XRD analysis detected a similar structure to the stage I annealing process, without the $\eta$ alumina phase. The amount of detected $\mathrm{Al}_{2.67} \mathrm{O}_{4}$ phase decreased to $63 \%$ while the $\gamma$-phase increased to $37 \%$. The increase in the amount of detected $\gamma$-alumina indicates the conversion of $F d \overline{3} m$ space group alumina crystals to the $F m \overline{3} m$ space group. The stage II' $^{\prime}$ annealed sample did not retain the same matches from the ICSD and changed to $\theta$-alumina with monoclinic symmetry belonging to the $C 2 / \mathrm{m}$ space group and a different $\gamma$-alumina (ICSD\#: 99836) belonging to the $I 4_{1} /$ amd space group.

The formation mechanism of alumina crystallites within the as-deposited nanotubes were of specific interest to provide an explanation for the onset of crystallization while the carbon scaffold provided by the internal CNTs was still present. The CNT scaffolds may initially limit the growth direction of a forming crystal from traversing towards the center of the alumina nanotube. Therefore, in situ crystallization was conducted with a focused TEM electron beam and observed temporally by recording of successive bright field images. Focused ion or electron radiation has the capability to induce localized crystallization, which occurs at a rate slow enough to
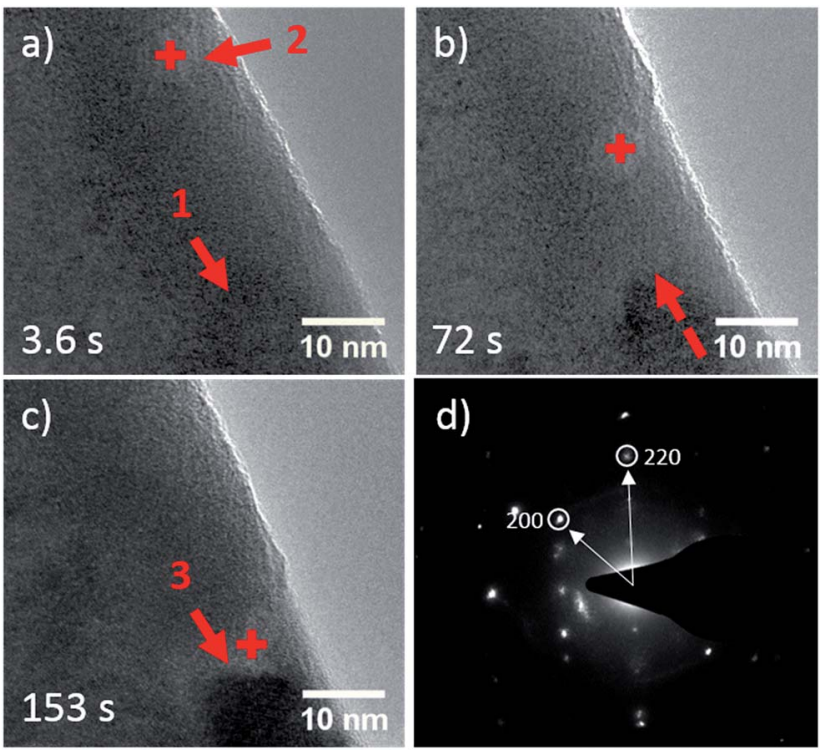

Fig. 7 (a) A crystal seed is nucleated at spot 1 with growth direction towards the induced defect present at spot 2. (b) The induced crystal growth propagates towards the induced defect. (c) The induced crystal collides with the induced defect at spot 3 and spreads laterally. (d) An electron diffraction image of the induced crystal. The indexed spots match well with known $d$-spacings for $\gamma$-alumina. A video of the above process can be viewed in the ESI S1.† 
record the propagation of such induced crystals. The injection site of electron irradiation will be brought to a stimulated amorphous state where an electron-induced rearrangement will occur beginning with the thermodynamically less stable bonds. ${ }^{27}$ Amorphous alumina primarily contains $\mathrm{AlO}_{4}$ with $\mathrm{AlO}_{5}$ and $\mathrm{AlO}_{6}$. The unstable $\mathrm{AlO}_{5}$ basic units are thought to be annihilated first leading the majority of the originally a-alumina sample to contain $\mathrm{AlO}_{4}$ and $\mathrm{AlO}_{6}$, constituents of $\gamma$-alumina. Final ratios of $\mathrm{AlO}_{4}$ and $\mathrm{AlO}_{6}$ in $\gamma$-alumina range from 3/7-4/6. ${ }^{28}$ Also, the conversion into $\gamma$-alumina does not rely upon thermal export from the local electron injection region. The increase in temperature due to electron irradiation within the alumina nanotubes can estimated by the following equations for a uniform film sample: ${ }^{29}$

$$
T=\frac{W_{0}\left[1+2 \ln \left(\frac{R}{r_{0}}\right)\right]}{4 \pi l_{0} k}, W_{0}=\varepsilon V \rho_{0} \pi r_{0}{ }^{2}
$$

where $W_{0}$ is total absorbed power, $R$ is the radius of the film supported within a hole of the TEM grid $\left(\sim 1.5 \times 10^{-6} \mathrm{~m}\right.$ for the carbon film supporting the alumina nanotube), $r_{0}$ the radius of the irradiated region $\left(5 \times 10^{-9} \mathrm{~m}\right), l_{0}$ the thickness of the film $\left(\sim 8 \times 10^{-8} \mathrm{~m}\right.$ for the side of the alumina tube between the CNT scaffold and vacuum), $k$ the thermal conductivity $\left(\sim 1.5 \mathrm{~W} \mathrm{~m}^{-1}\right.$ $\mathrm{K}^{-1}$ for ALD alumina $\left.{ }^{30}\right), \varepsilon$ the fraction of energy absorbed (typically 0.01 (ref. 31)), $V$ the accelerating voltage (all results acquired with $\left.2 \times 10^{5} \mathrm{~V}\right)$, and $\rho_{0}$ the current density $\left(4 \times 10^{6} \mathrm{~A}\right.$ $\mathrm{m}^{-2}$ as mentioned earlier). This translates to an estimated temperature rise of $\sim 5 \mathrm{~K}$. This temperature rise is negligible in the scheme of alumina phase changes therefore all of the induced crystallization can be attributed to electron-induced rearrangement of $\mathrm{Al}$ and $\mathrm{O}$ atoms. Depicted in Fig. 7 is the growth of a single grain of $\gamma$-alumina, which collides with a defect present in the nanotube. As seen in Fig. 7a, the crystal was initially seeded at point 1 and propagated in the direction of the defect at point 2 . The imaging window was then held constant, however, the nanotube had some drift as present in Fig. 7b, where the defect had an apparent shift downward from drift in imaging. The crystal continued to propagate and eventually collided with the defect at $153 \mathrm{~s}$, seen in Fig. 7c, equating to $\sim 0.16 \mathrm{~nm} \mathrm{~s}^{-1}$ propagation speed. Once connected with the defect, the nucleated crystal stopped propagating forwards and began to grow outwards. Once the crystal had grown to the limits, both to the CNT scaffold and the alumina/vacuum edge, the growth had dramatically slowed to where no appreciable propagation was observed. At this point an electron diffraction image was captured and indexed for the nucleated region and found to be a $\gamma$-alumina nanocrystal. Having established the single grain nucleation with propagation into a defect, it was logical to perform a double grain nucleation experiment. Depicted in Fig. 8a, an arbitrary section of the a-alumina nanotube was selected with an inset electron diffraction image corresponding the amorphous nature of the as-deposited alumina. Next, the first crystal was nucleated at the located denoted in Fig. 8b with corresponding electron diffraction image demonstrating the crystal nucleation. Then, the crystal propagated to the left at a speed of $\sim 0.30 \mathrm{~nm} \mathrm{~s}^{-1}$. Fig. $8 \mathrm{c}$ and d
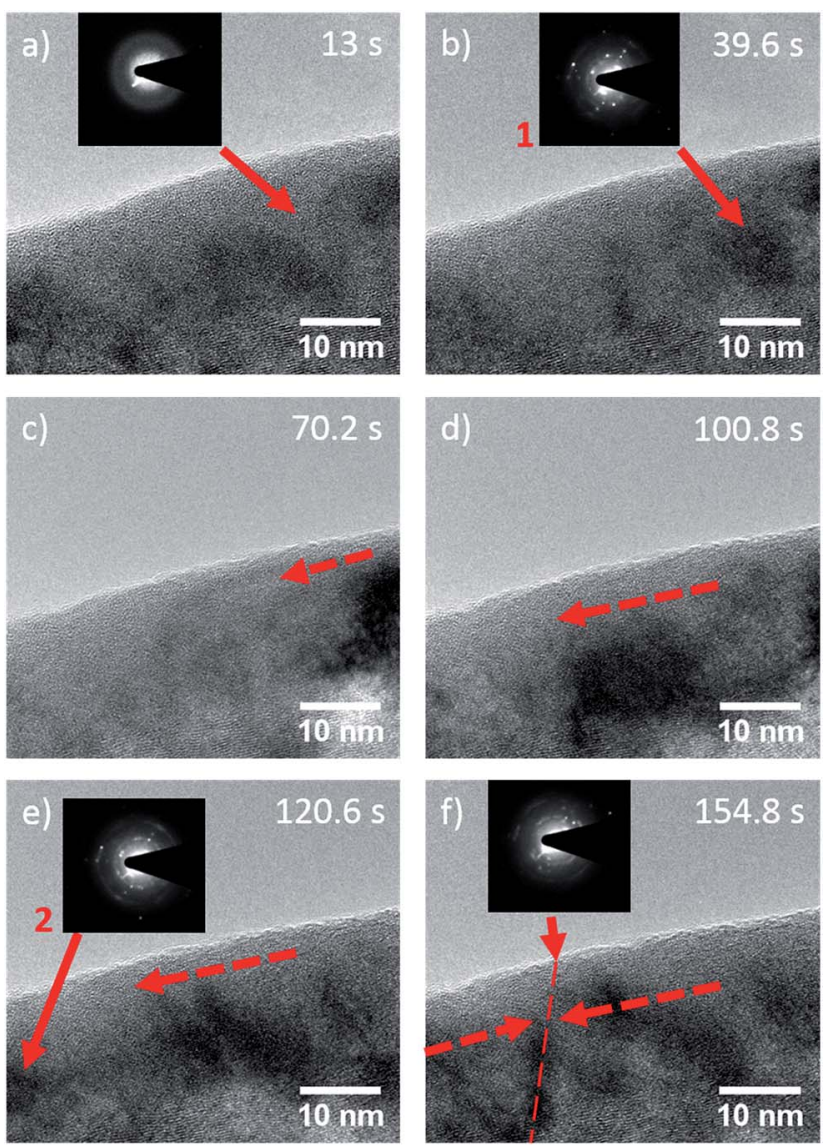

Fig. 8 (a) A profile view of an as-deposited, amorphous alumina nanotube prior to electron-induced crystallization. (b) A $\gamma$-alumina crystal is nucleated at spot 1 . (c) The nucleated crystal quickly propagates to the left. (d) The first induced crystal continues to propagate and begins to spread laterally. (e) A second $\gamma$-alumina crystal is nucleated at spot 2. (f) The second crystal collides with the first crystal and forms a defined grain boundary. Grain propagation was monitored with in situ brightfield recording and electron diffraction. A video of the above process can be viewed in the ESI S2.†

depict the first grain propagation. After $120.6 \mathrm{~s}$, the second grain was nucleated, as seen in Fig. 8e, with inset electron diffraction image denoting the crystalline nature of the second nanocrystal. The second crystal then propagated to the right with a speed of $\sim 0.17 \mathrm{~nm} \mathrm{~s}^{-1}$ until meeting the first crystal at the boundary indicated with a dashed line in Fig. 8f, with inset electron diffraction image of the formed grain boundary. Once the two grains had met, both grew outwards then halted any appreciable growth.

\section{Conclusions}

In summary, three different annealing routes were utilized for developing an understanding the phase transitions, which occur within an ALD alumina coating onto vertically aligned CNT scaffolds. TEM imaging and electron diffraction, TKD, XPS and XRD were used to analyze the progression in phases from as-deposited to annealed phases at varying temperatures at atmospheric pressure and ambient conditions to $950{ }^{\circ} \mathrm{C}$ (stage 
I) then $1200{ }^{\circ} \mathrm{C}$ (stage II), and directly to $1200{ }^{\circ} \mathrm{C}$ (stage II $)$. TEM imaging reveals an obvious change in morphology with the loss of the CNT scaffold upon all annealing treatments. Electron diffraction demonstrates the overall change in alumina phases between each annealing process. The phase that is detected within all annealed samples is $\gamma$-alumina with fractions of other metastable alumina phases detected as a result of annealing. TKD results indicate there are similar detected phases for stage I and II samples, with a reduction of $F d \overline{3} m$ and increase in $F m \overline{3} m$ space groups. In contrast, stage II $^{\prime}$ does not have any detected $F d \overline{3} m$ space group with only the $F m \overline{3} m$ space group along with a monoclinic alumina, in agreement with electron diffraction and XRD data. With XPS we were able to monitor the shift towards more metallic characteristics via monitoring of the chemical shift of the Al2p peak and the $\triangle B E$. XRD data revealed the detailed, bulk phase changes between each annealing process. The acquired results are in good agreement with electron diffraction and TKD. Finally, electron-induced crystallization was used to determine the dynamics of crystal formation with the as-deposited alumina on CNT scaffolds. The confinement of the alumina between the CNT and vacuum prevent normal crystal growth and promote parallel growth with spreading at defects and existing grains. The induced crystal phase was observed to be $\gamma$-alumina, in good agreement with other studies. With these results, we propose the crystallite size is largely governed by nucleation density and crystal growth propagation speeds driven by the spatial confinement of the alumina layer between the CNT scaffold and vacuum.

\section{Abbreviations}

$\begin{array}{ll}\text { CVD: } & \text { Chemical vapor deposition } \\ \text { CNT: } & \text { Carbon nanotube } \\ \text { MWCNT: } & \text { Multi-walled carbon nanotube } \\ \text { ALD: } & \text { Atomic layer deposition } \\ \text { PECVD: } & \text { Plasma enhanced chemical vapor deposition } \\ \text { TMA: } & \text { Trimethylaluminum } \\ \text { VANW: } & \text { Vertically aligned nanowire } \\ \text { TKD: } & \text { Transmitted Kikuchi diffraction } \\ \text { EBSD: } & \text { Electron backscatter diffraction } \\ \text { SEM: } & \text { Scanning electron microscope } \\ \text { TEM: } & \text { Transmission electron microscope } \\ \text { XPS: } & \text { X-ray photoelectron spectroscopy } \\ \text { XRD: } & \text { X-ray diffraction }\end{array}$

\section{Acknowledgements}

The authors would like to acknowledge Prof. Andrea Goforth for use of her XRD system and her recently graduated student, Dr Sheng Kuei Chiu for assistance with the XRD characterization using the XRD system funded by the NSF-MRI grant. The financial support for this research is supported in part by the NSF grant No. 1057565 and Portland state University (PSU) faculty enhancement awards as well as NSF CHE 1102637 and ONAMI awards. The ALD coating of CNTs was performed in the
OSU Materials Synthesis and Characterization (MaSC) Facility. The microscopy and spectroscopy characterization was performed at PSU's Center for Electron Microscopy and Nanofabrication (CEMN).

\section{Notes and references}

1 K. E. La Flamme, K. C. Popat, L. Leoni, E. Markiewicz, T. J. La Tempa, B. B. Roman, C. A. Grimes and T. A. Desai, Biomaterials, 2007, 28, 2638-2645.

2 H. Li, Y. Li, J. Jiao and H. Hu, Nat. Nanotechnol., 2011, 6, 645650.

3 L. Lampert, B. Timonen, S. Smith, B. Davidge, H. Li, J. F. Conley Jr., J. D. Singer and J. Jiao, Chem. Commun., 2014, 50, 1234-1237.

4 A. Boumaza, L. Favaro, J. Lédion, G. Sattonnay, J. B. Brubach, P. Berthet, A. M. Huntz, P. Roy and R. Tétot, J. Solid State Chem., 2009, 182, 1171-1176.

5 J. Hlavay and K. Polyák, J. Colloid Interface Sci., 2005, 284, 7177.

6 H. Pines and W. O. Haag, J. Am. Chem. Soc., 1960, 82, 24712483.

7 I. Levin and D. Brandon, J. Am. Ceram. Soc., 1998, 81, 19952012.

8 I. Levin, T. Gemming and D. G. Brandon, Phys. Status Solidi A, 1998, 166, 197-218.

9 R. Lizárraga, E. Holmström, S. C. Parker and C. Arrouvel, Phys. Rev. B: Condens. Matter Mater. Phys., 2011, 83, 094201.

10 C. Bae, H. Yoo, S. Kim, K. Lee, J. Kim, M. M. Sung and H. Shin, Chem. Mater., 2008, 20, 756-767.

11 J. Kim, Y. C. Choi, K.-S. Chang and S. D. Bu, Nanotechnology, 2006, 17, 355.

12 Y. T. Tian, G. W. Meng, T. Gao, S. H. Sun, T. Xie, X. S. Peng, C. H. Ye and L. D. Zhang, Nanotechnology, 2004, 15, 189.

13 J. Zhou, S. Z. Deng, J. Chen, J. C. She and N. S. Xu, Chem. Phys. Lett., 2002, 365, 505-508.

14 Q. Zhao, X. Xu, H. Zhang, Y. Chen, J. Xu and D. Yu, Appl. Phys. A, 2004, 79, 1721-1724.

15 J. M. Green, T. Gutu, L. F. Dong, J. Jiao, J. F. Conley Jr. and Y. Ono, Microsc. Microanal., 2006, 12, 676-677.

16 C. F. Herrmann, F. H. Fabreguette, D. S. Finch, R. Geiss and S. M. George, Appl. Phys. Lett., 2005, 87, 123110.

17 M. Meyyappan, L. Delzeit, A. Cassell and D. Hash, Plasma Sources Sci. Technol., 2003, 12, 205.

18 A. Gohier, C. P. Ewels, T. M. Minea and M. A. Djouadi, Carbon, 2008, 46, 1331-1338.

19 R. R. Keller and R. H. Geiss, J. Microsc., 2012, 245, 245-251. 20 N. Brodusch, H. Demers, and R. Gauvin, J. Microsc., 2013, 250, 1-14.

21 S. V. Prikhodko, S. Sitzman, V. Gambin and S. Kodambaka, Ultramicroscopy, 2008, 109, 133-138.

22 A. Mulligan, V. Dhanak and M. Kadodwala, Langmuir, 2005, 21, 8312-8318.

23 A. K. N. Kumar, S. Prasanna, B. Subramanian, S. Jayakumar and G. M. Rao, J. Appl. Phys., 2015, 117, 125307.

24 M. Halmann, A. Frei and A. Steinfeld, Energy, 2007, 32, 24202427. 
25 F. A. Cotton and G. Wilkinson, Advanced Inorganic Chemistry, Wiley, New York, 5th edn, 1988.

26 Z. Q. Li, C. J. Lu, Z. P. Xia, Y. Zhou and Z. Luo, Carbon, 2007, 45, 1686-1695.

27 M. Kaiser, M. Pieterson, L. Van and M. A. Verheijen, J. Appl. Phys., 2004, 96, 3193-3198.

28 R. Nakamura, M. Ishimaru, H. Yasuda and H. Nakajima, J. Appl. Phys., 2013, 113, 064312.

29 M. Liu, L. Xu and X. Lin, Scanning, 1994, 16, 1-5.

30 Z. Luo, H. Liu, Y. Feng, P. Ye, Y. P. Chen and X. Xu, Proc. ASME Summer Heat Transfer Conf., 2013, v001T03A005.
31 L. Ba, Y. Qin and Z. Wu, J. Appl. Phys., 1996, 80, 6170-6174. 32 A. Gohier, C. P. Ewels, T. M. Minea and M. A. Djouadi, Carbon, 2008, 46, 1331-1338.

33 K. Hata, D. N. Futaba, K. Mizuno, T. Namai, M. Yumura and S. Iijima, Science, 2004, 306, 1362-1364.

34 D. Bom, R. Andrews, D. Jacques, J. Anthony, B. Chen, M. S. Meier and J. P. Selegue, Nano Lett., 2002, 6, 615-619. 35 A. Saha, C. Jiang and A. A. Marti, Carbon, 2014, 79, 1-18.

36 C. Jiang, A. Saha, C. Xiang, C. C. Young, J. M. Tour, M. Pasquali and A. A. Marti, ACS Nano, 2013, 7, 4503-4510. 